\title{
Las prácticas espirituales del eremitismo peninsular altomedieval
}

\author{
VANESSA JIMENO GUERRA*
}

\section{The spiritual practices of the high medieval peninsular hermits}

\begin{abstract}
RESUMEN
Durante la antigüedad tardía comenzó a desarrollarse en la Península Ibérica un ascetismo cristiano basado en los modos de vida llevados a cabo por los Padres del

Desierto y predicados en las Sagradas

Escrituras. Sin embargo, las semejanzas que este fenómeno presenta con respecto

a algunas de las doctrinas filosóficas griegas de época helenística son evidentes. Así, el aislamiento, la contemplación o el ayuno como medio de purificación son prácticas comunes a ambos.

De esta manera, el presente trabajo pretende ofrecer un análisis del panorama del eremitismo peninsular durante la Alta

Edad Media en relación con dichos sistemas filosóficos.

PALABRAS CLAVE: Arquitectura excavada; Eremitismo; Alta Edad Media, Península Ibérica
\end{abstract}

\begin{abstract}
During the late antiquity started to develope a christian asceticism in the Iberian Peninsula which were based on the ways of life of the Fathers of the desert and preached in the Holy Scriptures. However, this phenomenom looks like some of the Greek philosophical doctrines of the Hellenistical period. Thus, the loneliness, the meditation or the fast as way of purification are common practices for both of them.

This way, the present study tries to offer an analysis of the peninsular hermits panorama during the High Middle Ages compared to these philosophical systems.
\end{abstract}

KEY WORDS:

Rock-cut architecture; Hermits; Early Middle Ages; Iberian Peninsula

El fenómeno del eremitismo cristiano, concebido como una forma de ascesis ${ }^{1}$, encuentra su origen de forma casi paralela en Mesopotamia, Siria, Egipto y Capadocia, así como en Occidente ${ }^{2}$. No obstante, la historiografía ha considerado tradicionalmente a Egipto como el germen del mismo ${ }^{3}$.

* Departamento de Patrimonio Artístico y Documental. Universidad de León. vjimg@unileon.es.

1 Voz «ascesis»: "Las reglas y prácticas encaminadas a la liberación del espíritu y el logro de la virtud». R.A.E. Diccionario de la Lengua Española. Vigésimo segunda edición [en línea]. Disponible en: http://buscon.rae.es/drael/SrvltConsulta?TIPO_BUS=3\&LEMA=ascesis. [Consultado: 24/05/2010].

2 BURTON-CHRISTIE, D., La palabra en el desierto. La escritura y la búsqueda de la santidad en el antiguo monaquismo cristiano, Madrid, Siruela, 2007, p. 52.

${ }_{3}$ Así por ejemplo, Ramón Teja señala que «el monacato surge, efectivamente, en la segunda mitad del siglo III en Egipto bajo la forma de anacoretismo y su símbolo más representativo fue san Antonio. (...) Es por tanto en el Egipto de finales del siglo III y comienzos del IV donde hay que buscar la expli- 
Las vocaciones no fueron exclusivamente masculinas, ya que existen ejemplos de mujeres que eligieron de forma absolutamente voluntaria esta conducta espiritual, manifestando, en muchos casos, una resistencia superior a la varonil ${ }^{4}$. Sin embargo, fueron figuras ilustres como la de San Antonio abad o San Pablo ermitaño las que otorgaron con sus conductas una gran trascendencia y popularidad a este tipo de vida, provocando, de esta manera, un incremento en el número de seguidores, así como la arribada de individuos deseosos de conocer a los Padres del desierto y su ideal de vida.

Los viajes y peregrinaciones, la literatura de carácter apologético, el tráfico de productos y objetos de diversa índole, así como las migraciones por parte de algunos monjes orientales contribuyeron a la difusión de esta expresión de vida cristiana en Occidente, aunque nunca llegaría a practicarse «con la misma intensidad ni con el mismo entusiasmo" ${ }^{6}$.

cación del fenómeno, al margen de la existencia de otras formas similares de anacoretismo en otros lugares, especialmente en Oriente». TEJA, R., Emperadores, obispos, monjes y mujeres. Protagonistas del cristianismo antiguo, Madrid, Trotta, 1999, p. 152. Igualmente, Ángel Canellas afirma que el origen del eremitismo se encuentra en este lugar. CANELLAS, A., «Noticias sobre eremitismo aragonés», España Eremítica, Leyre, 15 al 20 de sept., 1963, p. 257.

4 Torallas Tovar explica que, además de las comunidades urbanas de vírgenes, las «asistentes de los «recluidos»» y las mujeres ascetas que convivían con ascetas masculinos, existieron otras mujeres, aunque en número escaso, que decidieron libremente llevar una vida anacorética. De la misma manera apunta la presencia de «una variante de mujeres en el desierto», las cuales son denominadas como vírgenes itinerantes. TORALLAS TOVAR, S., «Hombres y mujeres en el desarrollo monástico egipcio de los siglos IV-V», en Carmen Alfaro Giner y Estíbaliz Tébar Megías (Eds.), Protai Gynaikes: Mujeres próximas al poder en la antigüedad, Valencia, Universidad de Valencia, 2005, pp. 161-171; MARCOS, M., «Los orígenes del ascetismo y el monacato en Hispania», Revisiones de Historia Antigua, III, (2000), p. 208. Asimismo, D. Antonio Viñayo informaba de la existencia de veinte mil mujeres eremitas en la diócesis egipcia de Oxyrhinkus. VIÑAYO GONZÁLEZ, A., "San Fructuoso de Braga. El hombre, el fundador, el Santo", en San Fructuoso y su tiempo (Estudios de divulgación sobre el creador de la Tebaida Leonesa y Patriarca del monacato español, publicados con motivo del XIII Centenario de su muerte, año 665), León, Imprenta Provincial, 1966, p. 201 y SIRA CARRASQUER PEDRÓS, M. y DE LA RED VEGA, A., Madres del desierto. Matrología I, Burgos, Monte Carmelo, 2000.

5 «Siguiendo los pasos de algunos anacoretas ilustres como Antonio, a mediados del siglos IV se formaron en el desierto al Sur de Alejandría, en los lugares de Nitria, Escete, Las Celdas y otros, grandes colonias de anacoretas». TEJA, R., «El demonio de la homosexualidad en el monacato egipcio», Codex Aqvilarensis, 8, (1994), p. 23. La monja Egeria, oriunda de la Gallaecia, o los historiadores romanos Paladio y Casiano son algunos de aquellos hombres y mujeres que sintieron curiosidad por la vida anacorética. Tanto es así, que sus escritos sobre el ideal ascético gozaron de una amplia trascendencia. GARCÍA COLOMBÁS, M., El monacato primitivo, Madrid, Biblioteca de Autores Cristianos, 2004, p. 47. Véase «La fama de estos monjes llegó hasta occidente. La hispana Egeria debió hablar mucho de ellos cuando regresara a Hispania después de su viaje por los santos lugares, y refiere entusiasmada que llegó a conocerlos en el transcurso de su periplo. La pía viajera confirma la existencia en Siria y Mesopotamia del culto a los hombres santos». MOLINA GÓMEZ, J. A., «El monacato cristiano en Siria. Introducción, problemas y propuestas», Antigüedad y Cristianismo, 15, (1998), p. 391. TEJA, R., «La increíble aventura de los «Padres del desierto»: Viajes y peregrinaciones al Egipto cristiano», en Joaquín Rubio Tovar, Margarita Vallejo Girvés y Francisco Javier Gómez Espelosín (Eds.), Viajes y visiones del mundo, Madrid, Ediciones Clásicas, 2008, pp. 129-144.

6 FERNÁNDEZ CATÓN, J. Ma.., Manifestaciones ascéticas en la iglesia hispano-romana del siglo IV León: Archivo Histórico Diocesano, 1962, pp. 120 y 133; TORRES, C., «Peregrinos de Oriente a Galicia en el siglo V», Cuadernos de Estudios Gallegos, 12, (1957), pp. 53-64; MOLINA GÓMEZ, J. A., «El monacato cristiano en Siria. Introducción, problemas y propuestas», Antigüedad y Cristianismo, 15, (1998), pp. 391-392. «Las «vidas de santos» se convirtieron en un género específicamente cristiano, la hagio- 
El origen de estas prácticas ascéticas bien puede tratarse de una derivación o adopción de los ejercicios espirituales llevados a cabo por algunas escuelas filosóficas de la antigua Grecia con el fin de alcanzar un ideal moral ${ }^{7}$. Así, el estoicismo, el pitagorismo, el platonismo, el neoplatonismo, el cinismo y, en última instancia, el orfismo, fueron algunas de aquellas doctrinas que defendieron el

grafía, iniciado con la Vida de Antonio que escribió en griego Atanasio de Alejandría y que se tradujo enseguida al latín con gran éxito de público. Circulaban también recopilaciones de «Sentencias de los padres del desierto" -la colección que se denomina Apophthegmata Patrum- y multitud de noticias biográficas y anécdotas recogidas por viajeros y reunidas en obras como la Historia Monachorum o la Historia Lausiaca». MARCOS, M., «Monjes ociosos, vagabundos y violentos», en Ramón Teja Casuso (coord.), Cristianismo marginado: rebeldes, excluidos, perseguidos I. De los orígenes al año mil. Actas del XI Seminario sobre Historia del Monacato, Aguilar de Campoo, 4 al 7 de agosto, 1997, p. 60; Fernández Ardanaz apunta como hecho frecuente «que la peregrinación incluyera una visita a los monjes de Egipto». Así, en el siglo IV, la noble romana Santa Paula peregrina viajó a Egipto con San Jerónimo con la finalidad de «visitar a los monjes que practicaban un elevado ascetismo, y de vuelta en Belén mandó construir un monasterio, donde después habitó». FERNÁNDEZ ARDANAZ, S., "Monaquismo oriental en la Hispania de los siglos VI-X», Antigüedad y cristianismo, 16, (1999), p. 204; LAWRENCE, C. H., El monacato medieval. Formas de vida religiosa en Europa occidental durante la Edad Media, Madrid: Gredos, 1999, pp. 29-31 y «Las peregrinaciones a Tierra Santa hasta el siglo VII d. C.», en Feliciano Novoa Portella (coord.), De Finisterre a Jerusalén. Egeria y los primeros peregrinos cristianos, Santiago, Xunta de Galicia, 2003, pp. 79-80.

7 En este sentido, Burton-Christie, haciéndose eco de Hugh White y Walter Hauser en The Monasteries of the Wâdi $n$ Natrûn, afirma que «la influencia de las escuelas filosóficas griegas sobre el origen del monaquismo es difícil de creer, puesto que la mayor parte de las principales figuras del movimiento monástico en sus comienzos, como Antonio, Amún, Pacomio y Macario eran, si no analfabetos, al menos personas de una educación muy limitada. Tampoco habrían tenido muchas oportunidades de viajar, y deben de haber tenido pocas posibilidades de contactar con filósofos paganos, que generalmente estaban en centros urbanos más grandes. La influencia del pensamiento griego se percibe, sin duda, en la literatura monástica cuando el movimiento estaba ya desarrollado, durante el siglo IV, especialmente en obras como la Historia Lausiaca y los escritos de Evagrio y Casiano. Sin embargo no hay ninguna razón para creer que el pensamiento filosófico griego hubiera desempeñado un papel significativo en las primeras etapas del movimiento monástico». BURTON-CHRISTIE, D., Op. Cit., pp. 293-294. Bien es cierto que el nivel de educación de muchos de primeros estos eremitas era ínfimo, sin embargo, no debemos olvidar que sus prácticas, como veremos posteriormente en el presente trabajo, estaban basadas en la meditación de las Sagradas Escrituras así como en su recitación. Es por ello que necesitaban saber leer para poder llevarla a cabo o, al menos, contar con alguien que pudiese leerlas por ellos.

Igualmente, Colombás informa de que «los primeros solitarios habían sido grandes enemigos de la filosofía griega, y la gran mayoría de sus sucesores perseveró en esta actitud cerrada», ya que "el monje es muy superior al filósofo, no tiene nada que envidiarle. (...) La antigua filosofía griega, con su terminología, sus conceptos e incluso sus ideales, va penetrando en la espiritualidad de los monjes en vías de sistematización. Este es un hecho innegable. Pero también parece indiscutible que no se puede enumerar la filosofía profana entre las fuentes de dicha espiritualidad, poniéndola al mismo nivel que la Escritura y la tradición». Sin embargo, más adelante, Colombás dice que no es viable construir un «sistema espiritual coherente sin servirse de la filosofía», cayendo así en contradicción. GARCíA COLOMBÁS, M., Op. Cit., pp. 471-475.

Por su parte, Fernández-Galiano señala que el cristianismo se apropió «de textos filosóficos y religiosos del mundo antiguo», entendiendo «por apropiación un proceso de adopción, no necesariamente fraudulenta, de ideas y valores en origen pertenecientes al mundo clásico, que la Iglesia habría de hacer suyos, y que el tiempo terminó legitimando». FERNÁNDEZ-GALIANO, D., «Un monasterio pitagórico: los terapeutas de Alejandría», Gerión, 11, (1993), p. 245. Igualmente, Mena Cabezas dice que en el mundo occidental el ascetismo surge en el mundo griego (orfismo, cultos mistéricos, pitagorismo, platonismo, estoicismo) como renuncia a los placeres y apetitos corporales con el fin de purificar el alma y desarrollar el conocimiento. MENA CABEZAS, I. R., «El ascetismo pentecostal gitano y la gestión corporal. Una aproximación desde la antropología del cuerpo", Athenea Digital: Revista de pensamiento e investigación social, 13, (2008), p. 3. 
abandono del mundo material para alcanzar la vida contemplativa, a través de la práctica de las virtudes ${ }^{8}$.

\section{EL DESARROLLO DEL EREMITISMO EN LA PENÍNSULA IBÉRICA}

Fernández Catón señalaba que fue principalmente en la segunda mitad del siglo IV cuando se produjeron las primeras manifestaciones ascéticas en la Hispania romana de la mano de aquellos hombres y mujeres paganas que decidieron convertirse al cristianismo ${ }^{9}$. Así pues, la Iglesia, asegurándose una buena formación cristiana para éstos, decide que lleven a cabo una serie de prácticas, «a fin de que reconozca[n] sus caídas pasadas y las deteste[n]", basadas en la renuncia de vicios y pasiones así como en la constante oración y penitencia ${ }^{10}$.

Fueron, por tanto, estas vírgenes, continentes ${ }^{11}$ y mártires hispano-romanos los iniciadores en la Península lbérica de la práctica individual de algunas de las enseñanzas promulgadas en las Sagradas Escrituras ${ }^{12}$. Así, a finales de la cuarta centuria, este tipo de conductas habían penetrado, incluso, en la alta sociedad hispana, siendo Poemenia y Egeria un buen ejemplo de ello ${ }^{13}$.

Por otro lado, y paralelamente, se produjo en la Península el desarrollo del movimiento ascético priscilianista ${ }^{14}$, el cual poseía algunas semejanzas con el fenó-

8 Testón Turiel manifiesta que «se denota una necesidad de búsqueda de pureza, de paz, de soledad y de unión con Dios, todo esto lo intentarán encontrar en un primer momento en la filosofía especialmente en las escuelas griegas que estaban surgiendo en este periodo». Así, dice que «las más importantes fueron el movimiento pitagórico, el cinismo y el estoicismo", apuntando como última corriente el neoplatonismo, «que será el último intento de la filosofía de construir una síntesis entre el helenismo y la espiritualidad oriental, especialmente frente al Cristianismo». TESTÓN TURIEL, J. A., El monacato en la Diócesis de Astorga en los periodos antiguo y medieval. La Tebaida berciana, León, Universidad de León, 2008, p. 42.

9 FERNÁNDEZ CATÓN, J. Mํa., Op. Cit., p. 26.

10 Ibidem, pp. 26-28. El encorchetado es nuestro.

11 Con este término nos estamos refiriendo a aquellos hombres que practican la continencia sexual.

12 «Cierto que por esta época el ascetismo se debía practicar con cierto carácter individual, especialmente entre los continentes clérigos; la vida comunitaria de ascetas a finales del siglo IV en España presenta un grave problema para su estudio por la escasez de fuentes (...); sin embargo, todos los cánones dan a entender que entre los ascetas (...) existía una mutua relación de ayuda espiritual, guiados por el mismo ideal ascético». Ibidem, p. 59. «Desde principios del siglo IV hallamos testimonios de la existencia en la península de ascetas y vírgenes, sobre todo de estas últimas, para las que legisla en sus cánones el Concilio de Illiberis». GIBERT, G. M., «El eremitismo en la Hispania romana», España Eremítica, Leyre, 15 al 20 de sept., 1963, p. 41. «La práctica de ascesis sexual, bien en forma de virginidad perpetua o de continencia dentro del matrimonio, estuvo muy difundida en las comunidades cristianas de los primeros siglos, tanto en Oriente como en Occidente». MARCOS, M., Los orígenes del..., p. 207.

13 Ibidem, pp. 61 y 63-66; BLÁZQUEZ MARTíNEZ, J. Mㄹ.., «El monacato de los siglos IV, V y VI como contracultura civil y religiosa", en María José Hidalgo de la Vega (coord.), La historia en el contexto de las ciencias humanas y sociales. Homenaje a Marcelo Vigil Pascual, Salamanca: Universidad de Salamanca, 1989, p. 105; MARCOS, M., Los orígenes del..., pp. 223 y 225-228; FERNÁNDEZ ARDANAZ, S., art. cit., p. 205 y TEJA, R., op. cit., p. 199.

14 No es objeto del presente estudio entrar en las controversias que ha suscitado este movimiento. Tan sólo pretendemos recoger el carácter ascético de sus prácticas en la Hispania del siglo IV. Para más 
meno eremítico en cuanto a aislamiento se refiere, ya que, como señalan algunos cánones conciliares de la época, el retiro en montes y cavernas eran prácticas habituales ${ }^{15}$.

En este sentido, algunos autores afirman que la presencia de solitarios en la Península, al modo oriental, no se desarrolló hasta el siglo V. Así, Martínez Tejera asegura que una de las primeras provincias en manifestarse fue la Tarraconense, siendo ejemplo de ello la figura de San Victoriano de Asán, el cual fue «comparado en su epitafio con San Pablo ermitaño y con San Antonio ${ }^{16}$. No obstante, se conservan algunos testimonios escritos que nos informan de que este tipo de

información véase BLÁZQUEZ MARTÍNEZ, J. Ma․, «Prisciliano, introductor del ascetismo en Hispania. Las fuentes. Estudio de la investigación moderna», en Gonzalo Fatás (Ed.), I Concilio Cesaraugustano. MDC Aniversario, Zaragoza, 25 al 27 de sept., 1980, pp. 65-121; FONTAINE, J., «Panorama espiritual del Occidente peninsular en los siglos IV y V: Por una nueva problemática del priscilianismo », Primera reunión gallega de estudios clásicos, Santiago De Compostela, 1979, pp. 185-209; BARBERO DE AGUILERA, A., «El priscilianismo: ¿herejía o movimiento social?», en Conflictos y estructuras sociales en la Hispania antigua, Madrid, Akal, 1986, pp. 77-114; DE LA CRUZ DÍAZ MARTÍNEZ, P., «Ascesis y monacato en la Península Ibérica antes del siglos VI», I Congreso peninsular de Historia Antigua, Santiago de Compostela, 1986, pp. 205-226; DE LA CRUZ DÍAZ MARTíNEZ, P., «La recepción del monacato en Hispania», Codex Aqvilarensis, 5, (1991), pp. 131- 140; CARDELLE DE HARTMANN, C., «El priscilianismo tras Prisciliano, ¿Un movimiento galaico?», Habis, 29, (1998), pp. 269-290; OLIVARES GUILLEM, A., «Actitud del Estado romano ante el priscilianismo», Espacio, tiempo y forma. Serie II, Historia Antigua, 14, (2001), pp. 115-127; PIAY AUGUSTO, D., «Acercamiento prosopográfico al priscilianismo», Antigüedad y Cristianismo, 23, (2006), pp. 601-625 y FERNÁNDEZ CONDE, F. J., Prisciliano y el priscilianismo. Historiografía y realidad, Gijón, Trea, 2008, entre otros.

${ }_{15}$ Se trata de un movimiento cuyo máximo desarrollo se lleva a cabo a finales del siglo IV, a pesar de que su origen en la Península es desconocido, y estuvo caracterizado por el ayuno, la oración, la pobreza, la abstinencia, la virginidad así como la renuncia completa a todo lo que les vincula al mundo o al cuerpo. Fernández Catón asevera que «no parece que los priscilianistas se contentasen con sólo estas prácticas penitenciales; el concilio de Zaragoza condena otras dos: el andar con los pies desnudos y el vivir retirados en montes, descampados y cavernas». A ello añade que «no encontramos ninguna otra fuente por tales fechas donde se nos refleje este tipo de vida ascética. Serán en las épocas visigoda y prerrománica, cuando, existiendo aún durante los siglos $\mathrm{V}$ y VI este tipo anacorético, nazcan un sinfín de monasterios enclavados en lugares montañosos y agrestes excavados en las mismas peñas, como parecen demostrarlo ciertas iglesias de la citada época». Ibidem, pp. 69 y 90-91. Así, el canon II del primer Concilio de Zaragoza (397-400) estipulaba que «(...) ni se escondan en lo más apartado de su casa o de los montes aquellos que perseveran en estas creencias, sino que sigan el ejemplo de los obispos y no acudan a las haciendas ajenas, para celebrar reuniones (...)". Igualmente, el canon IV advertía de que «(...) en los veintiún días que hay entre el 17 de diciembre hasta la Epifanía que es el 6 de enero, no se ausente nadie de la iglesia durante todo el día, ni se oculte en su casa, ni se marche a su hacienda, ni se dirija a los montes ni ande descalzo, sino que asista a la iglesia (...)». VIVES, J., Concilios visigóticos e hispano-romanos, Barcelona-Madrid, CSIC, 1963, pp. 16-17. En este sentido, Fernández Catón plantea unos interesantes interrogantes al respecto: «¿vivían así habitualmente o solamente en los días que ellos consideraban de mayor penitencia para la Iglesia?, ¿qué vida llevaban?, ¿de dónde pudo copiar el priscilianismo este género de vida?, ¿recibió España influencia del Oriente en este punto concreto?. La vida monástica que encontramos a veces en periodo visigodo ¿es una continuación de la vida anacorética priscilianista?». FERNÁNDEZ CATÓN, J. Mª., Op. Cit., p. 121. «Que en el occidente peninsular la pervivencia del anacoretismo pudiera tener raíces priscilianistas, parece fuera de duda, dada la situación dominante de los siglos IV y V». DÍAZ Y DÍAZ, M., «El monacato fructuosiano y su desarrollo», El monacato en la diócesis de Astorga durante la Edad Media, Astorga, 15 al 17 de diciembre, 1994, pp. 34-35.

16 DE LA CRUZ DÍAZ MARTÍNEZ, P., La recepción del monacato..., p. 140 y MARTÍNEZ TEJERA, A. M., «La realidad material de los monasterios y cenobios rupestres hispanos (siglos V-X)», Monjes y monasterios hispanos en la Alta Edad Media, Palencia, Fundación Santa María La Real y Centro de Estudios del Románico, 2006, p. 64. 
vida se había iniciado con anterioridad. De esta manera, tomando como fuente el Menologio de los griegos, aquel publicado por el cardenal Albani en 1727, podemos aseverar que el primer eremita cristiano que hubo de la Península lbérica fue un hombre llamado Osio, prelado asistente al concilio de Elvira celebrado en el siglo IV ${ }^{17}$. De la misma manera, las Memorias Sagradas del Yermo de Córdoba nos informan de que fue éste mismo el introductor de este tipo de vida en la antigua Hispania: «(...) y esto hace ver, que la vida eremítica y monástica en Córdoba, debe su principio a Osio su primer Monge, y Anacoreta, antes que en el resto de todo el occidente se huviese conocido este género de vida. Ni debemos detenernos en apurar la distinción de Monges, y Ermitaños: igualmente Osio estableció uno, y otro modo de vida, como consta del testimonio alegado del antiguo Menologio de los Griegos, y en efecto los Monges de Cordoba tenían sus retiros en chozas, o cuevas en las cercanías de los Monasterios, y en lo más áspero de las montañas, práctica acreditada con el exemplo de todos los antiguos Monges de Egypto, y Palestina, de que abundan historias ${ }^{18}$.

Avanzando en el tiempo, en La Rioja del siglo VI destaca el discípulo de Félix de Bilibio, San Millán ${ }^{19}$, sobre el que Gonzalo de Berceo contaba que se retiró en soledad a una cueva en la que cometía duras penitencias sobre su cuerpo y practicaba la vigilia y la oración diaria ${ }^{20}$.

Con todo, a finales del periodo visigodo, este fenómeno había alcanzado un notable desarrollo, de manera especial, en tierras del Bierzo ${ }^{21}$. Ejemplo de ello

17 Véase, PÉREZ DE URBEL, J., Los monjes españoles en la Edad Media, Vol. I, Madrid, Ancla, 1933, p. 88; SÁNCHEZ HERRERO, J., Historia de la Iglesia en España e Hispanoamérica. Desde sus inicios hasta el siglo XXI, Madrid, Sílex, 2008, p. 30 o TESTÓN TURIEL, J. A., Op. Cit., p. 83, entre otros.

18 SÁNCHEZ DE FERIA Y MORALES, B., Memorias sagradas del yermo de Córdoba. Desde su inmemorial principio hasta de presente, Córdoba, Oficina de Don Juan Rodríguez de la Torre, 1782, pp. 12 13.

19 Ibidem, p. 65; DÍAZ Y DÍAZ, M., «La vida eremítica en el reino visigodo», España Eremítica, Leyre, 15-20 de sept., 1963, p. 50. "Entendió que el mundo era pleno d enganno, qerié partirse $d$ elli e ferse ermitanno; de levar non asmava nin conducho nin panno, faciéseli el día más luengo que un anno. Asmó un buen consejo, todo Dios lo obrava, que por prender tal vida doctrina li menguava; sopo que sant Felices en Bilivio morava, la ora de verlo, ver no la cuidava". DE BERCEO, G., La vida de San Millán de la Cogolla (estudio y edición crítica por Brian Dutton), London, Tamesis Books, 1984, p. 88. Para el caso que nos ocupa, no utilizamos la obra escrita por Braulio de Zaragoza, sino la realizada por Gonzalo de berceo, debido a que nuestro objetivo no es realizar un análisis exhaustivo del fenómeno eremítico peninsular sino de aquellos datos más relevantes que puedan servir como justificación a las prácticas ascéticas que desarrollamos en el presente estudio.

20 «Ficó el omne bono en las cuevas sennero, al so señor sirviendo como buen caballero; martiriava sus carnes como leal obrero, qerié a todas guisas merecer el dinero. Reçava bien sus oras, toda su salmodía, los imnos e los cánticos, toda la ledanía; rezava so salterio por uso cada día, con todo est lazerio avié grand alegría. (...) Decirvos non podriemos todas ues trasnochadas, nin todos los logres en qi tovo posadas; destajarvos qeremos de las fuertes andadas, sacarlo de los yermos a las tierras pobladas". Ibidem, pp. 91-92 y 98.

${ }^{21}$ FERNÁNDEZ CONDE, F. C., La religiosidad medieval en España. Alta Edad Media (siglos VII-X), Gijón, Trea, 2008, p. 161. De igual manera, Testón Turiel destaca durante el periodo visigodo la importancia que ostentó el ámbito berciano en cuanto al fenómeno eremítico se refiere, afirmando que «aquí se llegará a emular la obra de los grandes padres de la Tebaida egipcia, en todos los órdenes de la consagración a Dios». TESTÓN TURIEL, J. A., Op. Cit., p. 189. 
son las figuras de San Valerio, sus discípulos Saturnino, Evagrio y Juan, así como el considerado fundador de la tebaida berciana, San Fructuoso ${ }^{22}$. Éste último, al gusto de Casiano ${ }^{23}$, practicó en un primer momento la vida cenobítica para retirarse, posteriormente, a vivir en soledad ${ }^{24}$.

Igualmente, una mujer eremita llamada Benedicta decidió vivir durante un tiempo en la soledad del desierto berciano para luego fundar, junto con San Fructuoso, un monasterio para las ochenta vírgenes que a ella se acercaron en busca de aquella ansiada perfección espiritual ${ }^{25}$.

Durante los siglos posteriores destacaron figuras como la del obispo San Froilán en el siglo IX o Manilano en la décima centuria, del que «se sabe que hizo durante algún tiempo vida anacorética en el eremitorio del Valle del César, en tierras de León » ${ }^{26}$, además de la presencia de otros muchos recogidos en la documentación de la época ${ }^{27}$.

\section{EL CAMINO HACIA LA DIVINIDAD}

El principal y único objetivo que persiguieron estos ascetas fue alcanzar la perfección espiritual, acercarse progresivamente a Dios, a su contemplación, y, por ende, conseguir la salvación eterna y el paraíso perdido ${ }^{28}$. Como ejemplo de ello

22 «El Bierzo leonés fue un hervidero de anacoretas y eremitas desde, al menos, los tiempos de San Fructuoso, y de su existencia aún quedaban testigos en el último cuarto del siglo $X$ y en fechas tan avanzadas como en el segundo cuarto del siglo XII». MARTÍNEZ TEJERA, A. M., Op. Cit., p. 79.

23 «Aunque estaba convencido de que el anacoreta representaba la forma más elevada de vida cristiana, consideró la vida cenobítica como una preparación necesaria para ella». LAWRENCE, C. H., Op. Cit., p. 31.

${ }_{24}$ A lo largo de la historia, aquellos individuos que profesaban un ideal de vida religiosa en soledad han sido denominados de múltiples maneras. Así, en muchos casos, se han aplicado los términos asceta, eremita, anacoreta, ermitaño, monje solitario, etc., sin ningún tipo de escrupulosidad. En este caso, según San Isidoro, San Fructuoso recibiría el nombre de anacoreta y no de eremita ya que, con anterioridad a su aislamiento, ha disfrutado de una vida en comunidad. No obstante, en nuestro estudio utilizaremos los eremitas y los anacoretas indistintamente ya que ambos comparten la misma forma de vida. DE SEVILLA, I., Etimologías, I (Ed. bilingüe preparada por J. OROZ RETA), Madrid, Biblioteca de Autores Cristianos, 1982, p. 683.

25 DÍAZ Y DÍAZ, M. C., La vida de..., pp. 107-109.

26 ARIAS, M., «La vida eremítica en Galicia», España Eremítica, Leyre, 15 al 20 de sept., 1963, p. 368.

27 Así, en una donación del 940 realizada por el rey Ramiro II a Peñalba aparecen recogidos entre los testigos de la misma seis anacoretas, como así se intitulan, que responden a los nombres de Zanón, Zitani, Baldredo, Ramiro, Sancho y Diego. QUINTANA PRIETO, A., Peñalba (Estudio histórico sobre el monasterio de Santiago de Peñalba), León, Imprenta Provincial, 1963, p. 120.

28 GARCÍA DE CORTAZAR, J. A., «El hombre medieval como «homo viator»: peregrinos y viajeros», IV Semana de Estudios Medievales, Nájera, 2 al 6 de agosto, 1993, p. 11. Algunos autores como Colombás defienden la necesaria presencia de dos factores para poder llevar a cabo este camino. Así, por un lado se encontraría la voluntad del hombre, cuyo estímulo es la compunción, y, por otro, la gracia divina. Con ello pretendían buscar «el paraíso perdido. Se esforzaban denodadamente por recobrar el «estado natural» en que el hombre fue creado. Ambicionaban la plenitud de los dones de que gozaba Adán antes del pecado: su amistad familiar con Dios, la compañía de los ángeles, su dominio sobre todas sus potencias y facultades y sobre la creación entera, de la que había sido constituido rey». Así, el hombre, 
podemos citar la narración que realiza el monje Bonelo a San Valerio cuando le comenta el miedo que siente ante el inevitable juicio final ${ }^{29}$ : «Tiempo atrás estuve recluido en un encierro angosto y apartado, y con la mayor diligencia, por temor al juicio del Señor, sometí mi cuerpo a una rigurosísima abstinencia; y más aún, todas las prácticas requeridas por mi vida de penitente las llevaba a cabo en medio de una enorme penuria»30.

En esta búsqueda de la divinidad, el individuo llevaba a cabo una serie de ejercicios de purificación, tanto físicos como mentales, basados en la rigurosidad y dureza predicadas en las Sagradas Escrituras, con el fin de eliminar los vicios y adquirir las virtudes ${ }^{31}$. En palabras de Mar Marcos, «para alcanzar el dominio de sí, la apatheia que buscaban también los filósofos paganos, había que mortificar el cuerpo: dieta vegetariana escasa, ayunos, vigilia, sed, oración y labor incesante para mantener la mente ocupada; trabajo como autodisciplina y hasta mutilaciones»32.

De este modo, San Frutos y sus hermanos, Valentín y Engracia, decidieron repartir entre los pobres sus posesiones y retirarse del mundo practicando el eremitismo a orillas del Duratón ${ }^{33}$ : «La vida, y la penitencia que hicieron en aquel De-

«purificación tras purificación, se va espiritualizando más y más, va acercándose progresivamente a la pureza total de su condición primera, y, por consiguiente, se hace cada vez más capaz de ver a Dios, que es la simplicidad infinita». GARCÍA COLOMBÁS, M., Op. Cit., pp. 508-509, 529, 644 y 745.

${ }_{29}$ Como bien recoge Fernández Conde, existía una mentalidad apocalíptica en los ambientes eremíticos que generaba una cierta preocupación ante la venida del Anticristo, la Parusía, el fin del mundo y el Juicio Final, manifestada en muchos de sus escritos. FERNÁNDEZ CONDE, F. J., La religiosidad medieval en España. Alta Edad Media (siglos VII-X), Gijón, Trea, 2008, pp. 191-205.

30 DíAZ Y DÍAZ, M. C., Valerio del Bierzo. Su persona, su obra, León, Centros de Estudios e Investigación «San Isidoro», 2006, p. 211.

31 Fernández Catón señalaba para el análisis del ascetismo en la iglesia hispano-romana del siglo IV que las causas u origen de éste son «comunes para todas las regiones y basadas sobre los consejos evangélicos principalmente». FERNÁNDEZ CATÓN, J. Mā., Op. Cit., p. 26. «De las diversas fuerzas que dieron origen y definieron la búsqueda de santidad en el monaquismo primitivo, la Escritura es una de las más fundamentales e influyentes. Algunos textos clave de la Escritura, especialmente los que tienen que ver con la renuncia y el despego, están en los orígenes del monaquismo del desierto y sirvieron como fuente de inspiración para todo el movimiento». Para la interpretación de ésta, «el silencio, la praxis y la pureza de corazón se consideraban precondiciones morales importantes». BURTON-CHRISTIE, D., Op. Cit., pp. 22-23. Blázquez Martínez, en su estudio sobre el monacato de los siglos IV, V y VI, recogía que la Historia Lausiaca informaba de cómo los ascetas se sabían la Biblia de memoria. BLÁZQUEZ MARTÍNEZ, J. M ${ }^{a}$., Op. Cit., p. 115. «So also is it with their work. One works of the land as a labourer, another in the garden, another at the forge, another in the bakery, another in the carpenter s shop, another in the fuller s shop, another weaving the big baskets, another in the tannery, another in the shoemaker $s$ shop, another in the scriptorium, another weaving the young reads. And they learn all the scriptures by heart». Historia Lausiaca (32.12) [en línea]. Disponible en:

http://www.tertullian.org/fathers/palladius_lausiac_02_text.htm\#C32. [Consultado: 12/05/2010] y GARCÍA COLOMBÁS, M., Op. Cit., p. 541.

${ }^{32}$ MARCOS, M., Monjes ociosos,..., p. 59. Asimismo, Colombás señala que «la compunción constituye el punto de partida. Luego que el monje ha renunciado al mundo, se aplica con ardor al ascetismo, afligiendo su cuerpo con ayunos y vigilias y perseverando en la oración. Firme en su propósito de alcanzar la perfección espiritual, atraviesa sucesivamente etapas difíciles y turbulentas, y otras tranquilas y llanas». GARCÍA COLOMBÁS, M., Op. Cit., p. 512.

${ }_{33}$ Así lo dice la Biblia: «Si quieres ser perfecto, ve, vende lo que tienes y dáselo a los pobres. Así tendrás riquezas en el cielo. Luego ven y sígueme». Mateo, 19:21. 
sierto, parece que el mismo Desierto la publica: pues todo era rigor aún a la vista; sin que ningún sentido tuviese aún los deleites que son lícitos: el ayuno continuo: la vigilia incesante: el alimento hiervas: la bebida mezclada con lágrimas: ningún trato, ni memoria del mundo: toda la conversación y atención en los Cielos. De este modo anidando como Águilas en lo más alto de las peñas, miraban perpetuamente hacia la región de la luz, orando al Sol de Justicia, para que desterrase las sombras que tanto oscurecían la tierra» ${ }^{34}$.

Se trata de un viaje en el que el eremita asciende desde el mundo material e imperfecto hacia Dios similar al camino que, según Platón, recorre el alma del hombre para alcanzar el verdadero conocimiento. Sin embargo, mientras que para el filósofo este ascenso se tiene que llevar a cabo recorriendo una serie de estadíos que desembocan en una meta ulterior, en el caso de los ascetas éstos se producen de forma simultánea ${ }^{35}$. No obstante, en ambos casos, la vía para llegar a adquirir ese conocimiento es el amor ${ }^{36}$.

Aunque no todos practicaron las mismas conductas, el aislamiento, la oración y la mortificación física son los ejercicios más generalizados en este viaje místico. Así, el retiro es, para el asceta, la base imprescindible para poder llevar a cabo esa perfección espiritual y llegar a la divinidad, como señala uno de los apotegmas de los Padres del yermo: «Un hermano preguntó a un anciano diciendo: «¿Qué es el recogimiento y cuál es su utilidad?» El anciano respondió: «El recogimiento es permanecer en la celda en conocimiento y temor de Dios, alejado del rencor y sentimiento de superioridad. Tal recogimiento es origen de todas las virtudes y protege al monje de los rayos inflamados de los enemigos, impidiendo que nos hieran. ¡Oh recogimiento, progreso de solitarios! ¡Oh recogimiento, camino del Reino de los Cielos! ¡Oh recogimiento, madre de la compunción! ¡Oh recogimiento, que nos procura la penitencia! ¡Oh recogimiento, espejo de las faltas que enseña al hombre sus carencias! ¡Oh recogimiento que nos evita lágrimas y gemidos! ¡Oh recogi-

${ }^{34}$ FLÓREZ, E., España Sagrada, Theatro Geographico-Historico de la Iglesia de España, VIII, Madrid, Imprenta de José Rodríguez, 1860, p. 91.

35 «Así pues, cuando a partir de las realidades visibles se eleva uno a merced del recto amor de los mancebos y se comienza a contemplar esa belleza de antes, se está, puede decirse, a punto de alcanzar la meta. He aquí, pues, el recto método de abordar las cuestiones eróticas o de ser conducido por otro: empezar por las cosas bellas de este mundo teniendo como fin esa belleza en cuestión y, valiéndose de ellas como de escalas, ir ascendiendo constantemente, yendo de un solo cuerpo a dos y de dos a todos los cuerpos bellos y de los cuerpos bellos a las bellas normas de conducta, y de las normas de conducta a las bellas ciencias, hasta terminar, partiendo de éstas, en esa ciencia de antes, que no es ciencia de otra cosa sino de belleza absoluta, y llegar a conocer, por último, lo que es la belleza en sí». PLATÓN, El banquete (traducción de Luis Gil), Barcelona, Orbis, 1983, p. 93.

${ }^{36}$ En el caso del eremita es el amor a Dios mientras que para Platón es el amor a la belleza. Como manifiesta Burton-Christie, «el amor era un aspecto central del mundo de los padres del desierto. Cualesquiera que fueran los motivos que pudieran haberlos llevado inicialmente al desierto, cualesquiera que fueran las luchas particulares que los ocuparon durante su estancia en él, el fin de todos sus anhelos se expresaba en última instancia en el amor». BURTON-CHRISTIE, D., Op. Cit., p. 247. «El amor de Dios constituye el principal motivo de la vida cristiana y, consiguientemente, la primera y más importante inspiración de la vida monástica. (...) Dios es el bien supremo, objeto de todo deseo. El es nuestra meta y nuestro fin». GARCÍA COLOMBÁS, M., Op. Cit., pp. 535-536. 
miento, que vuelve el alma luminosa! ¡Oh recogimiento, que engendra dulzura! ¡Oh recogimiento, que conduce al hombre al estado pacífico! ¡Oh recogimiento, que nos hace hablar con los ángeles! ¡Oh recogimiento, que ilumina el espíritu! ¡Oh recogimiento, compañero de discernimiento! ¡Oh recogimiento, que engendra todo bien, soporte para el ayuno, freno para la lengua, obstáculo para la glotonería! ¡Oh recogimiento, escuela de oración y lectura! ¡Oh recogimiento, calma para el pensamiento, puerto abrigado! ¡Oh recogimiento, que emociona a Dios, arma para los jóvenes, que conserva sin turbarlos a aquellos que quieren permanecer en su celda! ¡Oh recogimiento, yugo suave y carga ligera, que descansa y lleva a aquel que lo lleva! ¡Oh recogimiento, alegría del alma y del corazón! ¡Oh recogimiento, que no se preocupa más que de lo que le concierne, que habla con Cristo, que tiene sin cesar la muerte ante sus ojos! ¡Oh recogimiento, freno para los ojos, el oído y la lengua! ¡Oh recogimiento, que cada día y cada noche espera a Cristo, conservando encendida la lámpara, pues deseando a Cristo, cantas sin cesar: Pronto mi corazón; oh Dios, está mi corazón dispuesto! ¡Oh recogimiento, que suprime la frivolidad y que en vez de risas procura lágrimas a quien lo posee! ¡Oh recogimiento, madre de la piedad! ¡Oh recogimiento, enemigo de la imprudencia! ¡Oh recogimiento, prisión de pasiones! ¡Oh recogimiento, campo de Cristo, lleno de buena cosecha! ¡Sí, hermano, adquiere esta virtud acordándote de la muerte!»37.

De esta manera, «recogiéndose en sí mismo, aislándose del resto del mundo, el monje trascendía el plano físico, proyectándose, espiritualmente, a otras esferas de perfección interior» 38 .

No obstante, fueron algunos los que, debido a su fama y santidad, recibieron visitas y discípulos que incluso llegaron a convivir con ellos, provocando, en algunos casos, la aparición de cenobios ${ }^{39}$. En este sentido, con respecto a la figura de San Millán, Gonzalo de Berceo escribía: «Sonó la buena fama entre los riojanos, las nuevas de los yermos hicieron a los planos; moviéronse con esto los febles e los sanos por ver al sant onme e besarli las manos ${ }^{40}$.

San Fructuoso también sufrió las consecuencias de su popularidad, tanto por parte de hombres como de monjes: «Quanto más crecía su fama, tanto más se angustiaba el que ni en tan áspero desierto hallaba soledad, porque allí iban de todas partes a buscarle. Resolvió en fin apartarse de aquel sitio, y ocultarse en la aspereza de otros montes, donde Dios le guiaba para echar fundamentos a un nuevo Monasterio, donde hasta hoy quería ser servido. Sacaronle de allí los Monges de Compluto, que no podían vivir sin el consuelo, y ejemplo de su Padre: pero en fin

37 Apotegmas de los Padres del desierto (introducción, selección y versión de Martí Àvila i Serra), Barcelona, José J. de Olañeta, 2003, pp. 65-67.

38 GRANDE DEL BRÍO, R., Op. cit., p. 13.

39 Idem; DÍAZ Y DÍAZ, M., «La vida eremítica en el reino visigodo», España Eremítica, Leyre, 15 al 20 de sept., 1963, p. 57.

40 DE BERCEO, G., Op. cit., p. 93. 
llamándole el Señor, para que como sol alumbrase otras partes, siguió el norte del Cielo» ${ }^{41}$.

Sin embargo, algunos sólo recibían compañía en las estaciones de primavera y verano, ya que en cuanto el frío aparecía eran abandonados. Así lo narra San Valerio: "Como seguía viviendo en aquel monte, dominado por una inmensa penuria de necesidades de toda clase, en tiempo de bonanza venían bastantes muchachitos para aprender conmigo. Pero en cuando se acercaban los malos tiempos del invierno con sus lluvias, todos se marchaban, y yo me quedaba solo y pensando sólo en la muerte» ${ }^{42}$.

Aunque no todos permanecieron toda su vida en el mismo lugar y algunos de ellos vivieron al aire libre ${ }^{43}$, el "desierto ${ }^{44}$ de la mayor parte de los eremitas fue una cueva ${ }^{45}$ escondida, alejada del mundo, ubicada en lugares escarpados y de difícil acceso, que reuniese las funciones de oratorio y vivienda ${ }^{46}$.

${ }^{41}$ FLÓREZ, E., España Sagrada. Theatro Geographico-Historico de la Iglesia de España, XVI, Madrid, Revista Agustiniana, 2005, p. 33.

42 DÍAZ Y DíAZ, M. C., Valerio del Bierzo..., p. 291.

43 «No todos los anacoretas eligieron permanecer su vida entera en un mismo lugar, como Juan de Licópolis que no quiso cambiar su morada durante más de cuarenta años. Otros variaban de residencia constantemente, como había hecho Antonio, arquetipo de monje errante. (...) Abba Jorge el Ermitaño (...) peregrinó desnudo durante treinta y cinco años, antes de fijar su morada en las cumbres rocosas de la Cilicia». ACERBI, S., «Experiencia anacorética y medio natural: Un recorrido por la hagiografía del Oriente Cristiano», Nova et Vetera: Temas de vida cristiana, 67, (2009), pp. 164-166 y TEJA, R., «La increíble aventura..., p. 142.

44 Utilizamos el término desierto, en sentido figurado, para referirnos al lugar donde el eremita se retira a vivir en soledad. No olvidemos que el término eremita proviene del latín erem ta y éste, a su vez, del

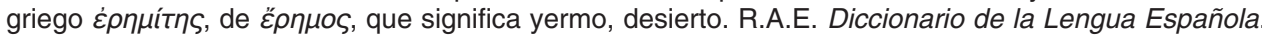
Vigésimo segunda edición [en línea]. Disponible en:

http://buscon.rae.es/drael/SrvltConsulta?TIPO BUS=3\&LEMA=eremita. [Consultado: 24/05/2010]. «El desierto ha sido, dentro de diversas tradiciones culturales, filosóficas y religiosas, un espacio - el espacioidóneo para la meditación y reflexión; espacio de superación y de encuentro consigo mismo y con la deidad, también lugar de huida del ruido del mundo». Es el «lugar de encuentro, hacia el que la divinidad atrae para intimar con el hombre». Apotegmas de los..., pp. 10 y 12.

45 «El simbolismo de la cueva y de la caverna se encuentra presente en el sustrato popular antiguo y en el trasfondo pagano. Era por tanto un hecho perfectamente natural que estos elementos hondamente arraigados en la conciencia colectiva emergieran también en el cristianismo primitivo, aunque se les otorgara un significado nuevo». MOLINA GÓMEZ, J. A., »La cueva y su interpretación en el cristianismo primitivo», Antigüedad y Cristianismo, 23, (2006), p. 863.

46 Así, San Fructuoso «buscó los más recónditos parajes del desierto, y tanto se cuidó de ocultarse en frondosas y retiradas espesuras, escondiéndose ya en lugares muy altos, ya en densos matorrales, ya incluso en peñascos que eran sólo accesibles a cabras monteses, que sólo podían verlo no con los ojos humanos sino los divinos". DÍAZ Y DÍAZ, M. C., La vida de San Fructuoso de Braga. Estudio y edición crítica, Braga, Diario do Minho, 1974, p. 93. De la misma manera, San Valerio dice: «encontré aquí el monasterio de Rufiana, apartado de todo contacto con el mundo, rodeado por la inmensa altura de unos montes como los Alpes galos, que parecía que no necesitaba paredes para sentirme encerrado; y según se entraba allí viniendo por la parte contraria de la habitable por haber unas finquitas, se encontraba un antiguo paso, hecho por la mano del hombre, tan pequeño y estrecho que en la roca excavada parecía un laberinto de acceso, por el cual se pasaba sólo de uno en uno con gran riesgo y temor. En este lugar, a un paso del vecino monasterio, en una altísima roca, se conserva el oratorio de San Fructuoso». DÍAZ Y DÍAZ, M.C., Valerio del Bierzo..., p. 313; MARTÍNEZ TEJERA, A. M., Op. Cit., p. 73. «La asociación celda-oratorio cubría las necesidades del eremita, al combinar las funciones de habitáculo con las de lugar de oración». GRANDE DEL BRÍO, R., Eremitorios medievales en las provincias de Salamanca y Zamora. Los monjes solitarios, Salamanca, Librería Cervantes, 1997, p. 135. Además, el sim- 
A partir de este retiro y renuncia de bienes materiales, el asceta comienza su viaje hacia Dios realizando una serie de penitencias y, en muchos casos, castigos físicos ${ }^{47}$. Dicha renuncia lleva implícita la condición de pobreza, por lo que el atuendo que estos hombres adoptarán a partir de ahora se distinguirá por la miseria y sobriedad, intentando demostrar con ello el desapego y desprecio a lo terrenal $^{48}$. No obstante, en algunos casos, la semidesnudez será el denominador común, ya que, debido a las extremas condiciones físicas que implica este tipo de vida, sus prendas se encuentran expuestas a las inclemencias atmosféricas y, por tanto, a la erosión de las mismas ${ }^{49}$. De esta manera, en ocasiones, recurrirán a las posibilidades que la naturaleza les brinda, como San Fructuoso que en algún momento de su vida vistió pieles de cabra ${ }^{50}$.

Igualmente, esta pobreza se encuentra manifestada en la alimentación. Así, aunque «el alimento ascético está condicionado por el clima»51, las dietas de los eremitas, al igual que las de los monjes, eran absolutamente vegetarianas, obteniendo los productos a partir de la flora de la zona en la que estaban instalados ${ }^{52}$.

bolismo que la cueva encierra es múltiple, pudiéndose ver en ella un retorno a la cavidad primigenia, a la Madre Tierra, al origen terrenal desde el que el eremita procurará «la elevación trascendente hacia lo celestial». Ibidem, pp. 15-18. «Conocida es, por otro lado, la asociación de las formas de hábitat rupestre con el mundo eremítico y semieremítico, donde la cueva ejerce un atractivo especial para el asceta, no sólo por sus ventajas materiales (economía, potencia constructiva, propiedades térmicas,...), sino también por el aislamiento que procura, la idea de desprendimiento que la acompaña, y el largo simbolismo que para el hombre, y para el hombre cristiano, tiene la cueva como lugar de catarsis y purificación». MONREAL JIMENO, L. A., "Arquitectura religiosa de oquedades en los siglos anteriores al Románico», en VII Semana de Estudios Medievales, 1997, pp. 241-242. Sirvan como ejemplo de ello los múltiples espacios conservados a lo largo de la geografía española. En este sentido véase AZKÁRATE GARAIOLAÚN, A., Arqueología cristiana de la Antigüedad Tardía en Álava, Guipúzcoa y Vizcaya, VitoriaGasteiz, Diputación Foral de Álava, 1988; MONREAL JIMENO, L. A., Eremitorios rupestres altomedievales. El alto valle del Ebro, Bilbao, Universidad de Deusto, 1989 y GRANDE DEL BRíO, R., Op. Cit., entre otros.

47 Gonzalo de Berceo cuenta de San Millán: «Ficó el omne bono en las cuevas sennero, al so señor sirviendo como buen cavallero; martiriava sus carnes como leal obrero, qerié a todas guisas merecer el dinero. (...) El buen siervo de Christo, tales penas levando, por las montannas yermas las carnes martiriando, iva enna Cogolla todavía pujando, e quanto más pujava más iva mejorando. (...) Y está oy en día, aún non es desfecho, un oratorio dicen qe él lo ovo fecho; allí dava a Dios de sus carnes derecho, martiriándolas mucho e dándolis mal lecho». DE BERCEO, G., Op. Cit., pp. 91, 95 y 96.

${ }_{48}$ Así, la Vita Fructuosi dice sobre el santo: «Mientras estaba echado en el suelo, el antiguo enemigo, siempre envidioso de todas las personas buenas, condujo al lugar en el que el santo oraba a un palurdo aldeano enfurecido. Cuando vió ante él al santo y lo descubrió solo, en medio de la enramada, con vestidos vulgares y con los pies descalzos y al aire, según se comportaba una mente grosera, despreciándolo por la vileza de su atuendo, acercóse más y más al santo confiado de insensata temeridad; y teniéndolo por fugitivo lo colmó de injurias denostándolo con palabras procaces, y, sin parase en barras, petulantemente, el rústico lo cubrió con toda clase de expresiones ofensivas». DíAZ Y DÍAZ, M. C., La vida de..., p. 99. Igualmente, San Millán »quarenta annos visco solo por la montanna, nunqa de omne ovo nin solaz nin companna, nin vito nin vestido, qe es mayor fazanna: confesor tan precioso non nació en Espanna!». DE BERCEO, G., Op. Cit., p. 97.

49 ACERBI, S., Op. Cit., pp. 169-170.

50 VIÑAYO GONZÁLEZ, A., Op. Cit., p. 179 y DÍAZ Y DÍAZ, M. C., La vida de..., p. 87.

51 ACERBI, S., Op. Cit., p. 171.

52 «El eremita tomaba, pues, lo que la tierra le ofrecía: hierbas y frutos silvestres componían su principal alimento». GRANDE DEL BRÍO, R., Op. Cit., p. 19. «La dieta ordinaria del monje era exclusivamente vegetariana y estaba integrada por legumbres, verduras, pan, vino, aceite, sal y vinagre». RIERA 
No obstante, el ayuno es una de las prácticas más habituales entre ellos, ya que «la gula es el atrio de los vicios» ${ }^{53}$ y no puede existir la contemplación de Dios sin «una estricta disciplina en el comer y beber» ${ }^{54}$. Así, es considerado como una purificación interior para poder llegar a la divinidad ${ }^{55}$. Este ayuno podía ser total o parcial, puesto que, en algunos casos, debe ser entendido como la privación de determinados alimentos como la carne o el vino ${ }^{56}$. En este sentido, la regla de San Fructuoso prohíbe comer carne a excepción de los enfermos y caminantes, siguiendo así la «constante tradición de los Padres de la Tebaida»57.

Esta práctica encuentra su razón de ser en el hecho de que la alimentación estaba íntimamente relacionada con los pensamientos, ya que «la glotonería, conduce sucesivamente a la lujuria, la avaricia y la acidia ${ }^{58}$. De esta manera, una dieta extremadamente hipocalórica provocaba el enfriamiento del cuerpo, ayudando así al asceta a concentrarse en Dios ${ }^{59}$.

Asimismo, la preparación de los alimentos ingeridos influía directamente en las mentes, es decir, «para alejar los estímulos eróticos y las fantasías lascivas se evitaban los alimentos que, calentados, excitaban el cuerpo, y raramente intervenía en la dieta del asceta algo cocido, no directamente recolectado en la naturaleza sino elaborado por el hombre» ${ }^{60}$.

MELIS, A., «Las restricciones alimenticias como recurso expiatorio en algunas reglas monásticas de los siglos VI y VII», Aragón en la Edad Media, 14-15, (1999), p. 1316.

$53 \mathrm{Ibidem}, \mathrm{p} .1303$. Así, es muy frecuente encontrar esta práctica en el Antiguo Testamento, por lo que los eremitas la llevaran a cabo. Podemos citar como ejemplo de ello 2 Samuel, 12: 16; 1 Reyes 22: 27; Isaías, 58: 4; Judit, 4: 13; Jonás, 3: 5 o Tobit, 12: 8, entre otros; GARCíA COLOMBÁS, M., Op. Cit., p. 574.

54 Idem

55 El ayuno es «una obra de penitencia y humildad, por la que se satisface por los pecados y se castiga el cuerpo y se humilla el alma. Es una obra de purificación y al mismo tiempo meritoria con que se alcanza el favor de Dios». Ibidem, p. 576.

56 «En las primeras comunidades cristianas dominaba un cierto rigorismo moral consistente en la abstinencia de vino y determinados alimentos (la carne, por ejemplo)». Apotegmas de los..., p. 14. Asimismo, Colombás señala que «para muchos monjes, a lo que parece, el ayuno lo era todo o casi todo en la vida espiritual. Ayunaban furiosamente, rivalizando entre sí hasta el agotamiento físico y espiritual. Tenían tanta aversión a ciertos alimentos como la carne y el vino, que, según todas las apariencias, los consideraban esencialmente malos». GARCÍA COLOMBÁS, M., Op. Cit., p. 582.

57 VIÑAYO GONZÁLEZ, A., Op. Cit., p. 227. «A ninguno se le concede licencia para gustar o tomar carne. No porque la consideremos como creatura indigna de Dios, sino porque la abstinencia de carne se estima útil y provechosa para los monjes, (...). Deberán pues vivir sólo de verduras y legumbres, y raras veces de peces de río o de mar». Reglas monásticas de la España visigoda. Los tres libros de las "Sentencias», (Introducciones, versión y notas de Julio Campos Ruiz e Ismael Roca Melia), Madrid, Biblioteca de Autores Cristianos, 1971, p. 142.

58 RIERA MELIS, A., Op. Cit., p. 1303. Igualmente, Colombás dice que «el ayuno es el principal enemigo de la glotonería, y, al vencer a ésta, resta energías al «espíritu de fornicación»». GARCíA COLOMBÁS, M., Op. Cit., p. 577

59 «Según una teoría muy difundida entre los moralistas cristianos antiguos, la gula era el primero de los vicios y la castidad, requisito imprescindible para la vida cenobítica, no se avenía con una dieta amplia, hipercalórica, fuerte». Idem. Asimismo, Hipócrates señalaba que «a los genitales el calor les provoca manifestaciones de placer y excitación, y el frio sensaciones de dolor y rechazo». HIPÓCRATES, «Sobre el uso de los líquidos», Tratados Hipocráticos, III (Introducción, traducción y notas: C. García Gual, J. Mā. Lucas de Dios, B. Cabellos Álvarez e I. Rodríguez Alfageme), Madrid, Gredos, 1986, p. 227.

60 ACERBI, S., Op. Cit., p. 174. 
Este tipo de conductas alimenticias no sólo eran propias de estos ascetas, ya que la consagración a la filosofía también implicaba una serie de ejercicios de purificación ${ }^{61}$. En este sentido, el filósofo griego Porfirio, en su tratado Sobre la abstinencia, señalaba que las pasiones y, con ello, la contaminación del alma, se producían a través de los sentidos ${ }^{62}$. Ejemplificaba este hecho en la figura de los sacerdotes egipcios, apuntando que «su régimen de comidas era frugal y simple: unos no probaban en absoluto el vino; otros, muy poco. Pues le achacaban lesiones nerviosas y el embotamiento de la cabeza, lo que suponía un obstáculo para la investigación, y también afirmaban que provocaba estímulos eróticos»63.

De la misma manera, la forma de vida pitagórica educaba en la abstinencia de determinados alimentos «que imposibilitaban la lucidez y claridad mental» de los hombres ${ }^{64}$. Así, Pitágoras renunció a beber vino, a comer carne, y tan sólo limitarse a ingerir «alimentos suaves y de fácil digestión» para poder conseguir «un sueño corto, vigilia, pureza de alma y una salud corporal perfecta e inquebrantable» 65 .

Además, el ayuno era considerado como el mejor método para alejar al demonio y sus posibles tentaciones ${ }^{66}$, y así lo aplicaba San Millán a propósito de la casa endemoniada de Onorio: «El santo mandamiento fue sobra bien tenido, todos en pan e agua en áspero vestido, entendió el demonio qe todo est roído era por su lazerio e por su mal venido. Complidos los tres dies, el ayuno pasado, cantó la missa el confessor onrrado; bendisso sal e agua el officio cantado, avié con estas nuevas grand pesar el pecado. Asmava esconderse en qualque socarrena, non fer ningún enojo a yantar nin a cena; irié Millán sue vía tener su qarentena, prendrié después derecho, doblarlis yé la pena»67.

Igualmente, la oración, la recitación de las Sagradas Escrituras, así como la meditación de éstas, además de conducir a la contemplación divina era una de las formas que tenía el eremita de protegerse ante las amenazas del maligno, por lo que, aún en la noche, permanecían despiertos, alerta en su tarea para combatir

61 En este sentido, Colombás manifiesta que «la historia de la filosofía nos muestra que tanto el estoicismo tardío como el neoplatonismo, esto es, las cofradías filosóficas de moda en tiempo de los padres y de los monjes primitivos, tienen una actitud muy parecida a la de éstos con respecto al uso de los alimentos", a lo que añade que estos solitarios no tomaron de ellos la costumbre de ayunar sino que seguían la «tradición judía y cristiana, consagrada por los santos de ambos Testamentos, y muy en particular por el mismo Jesucristo». GARCÍA COLOMBÁS, M., Op. Cit., p. 574-575.

62 A lo largo de toda la obra Porfirio se incide en este aspecto. PORFIRIO, Sobre la Abstinencia, (Traducción, introducción y notas de Miguel Periago Lorente), Madrid, Gredos, 1984.

63 Ibidem, cap. IV: 7, p. 196.

64 JÁMBLICO, Vida Pitagórica (Introducciones, traducción y notas de Miguel Periago Lorente), Madrid, Gredos, 2003, p. 63.

65 Ibidem, p. 33.

66 «La convicción de que, mediante el ayuno, se evitaban las tentaciones, se basaba tanto en la creencia popular de que ciertos espíritus malos entran en el hombre por la boca juntamente con los manjares, como en el deseo de evitar la «infección», particularmente en el periodo de luto por los muertos, y en la conexión que se había establecido entre ciertos demonios y determinados alimentos». GARCÍA COLOMBÁS, M., Op. Cit., pp. 576-577.

67 DE BERCEO, G., Op. Cit., p. 88. 
«las tentaciones y en particular la acedia, esa especie de tedio espiritual que acecha, más que a nadie, a quién aspira a la perfección» ${ }^{68}$.

En este sentido, San Valerio, a propósito de la monja Egeria, aconsejaba que: «(...) hay muchos caminos preparados por nuestros méritos que nos guían a la patria única de los reinos de los cielos, en la medida en que, con la ayuda del Señor, se mantenga en nosotros el coraje en nuestros trabajos, en nuestras vigilias, en nuestros ayunos y oraciones incesantes y aún en los diversos ejercicios del servicio divino que la regla impone, debemos prepararnos día y noche infatigablemente y abstenernos de toda clase de placeres prohibidos, de las seducciones de mundo y de las diversas faltas ${ }^{6}{ }^{\text {. }}$.

Además, esta práctica implicaba unas connotaciones psicológicas, ya que mediante determinados textos, el eremita sentía un alivio tanto físico como psíquico ${ }^{70}$.

De otra parte, el desconocimiento existente ante la segunda parusía del Señor provocaba esta vigilia ${ }^{71}$, la cual, al mismo tiempo, se encontraba íntimamente relacionada con la ingesta de alimentos así como con la evasión de sueños peligro$\operatorname{sos}^{72}$.

68 VAUCHEZ, A., La espiritualidad del occidente medieval (siglos VIII-XII), Madrid, Cátedra, 1985, p. 39; BURTON-CHRISTIE, D., Op. Cit., pp. 121 y 190-191. Así, la Biblia señala: «sed sobrios y velad; porque vuestro adversario el diablo, como león rugiente, anda alrededor buscando a quien devorar». $1 \mathrm{Pe}$ dro, 5: 8. San Valerio en sus obras narra una historia que ejemplifica perfectamente la fuerza de la oración ante el diablo. Así, dice: «En otro momento enseñaba yo a leer a un chiquillo, alumno mío, al que la generosidad divina le había dado tal capacidad de memoria que trabajando medio año consiguió retener en la cabeza todo el Salterio con los Cánticos. Un día a la hora de sexta estaba sentado al trabajo, y leía delante de mí, cuando empezó a gritar diciéndome: «Qué es lo que estoy viendo?»; y yo le dije: «¿Qué ves?», y me respondió: «Pues veo un ángel del Señor cuyo rostro refulge como el sol, cuyos vestidos son más blancos que la nieve, que me dice que por tu causa vino enviado por el Señor, para llevarte a la presencia de su majestad, para darte recompensa por tus obras». Y yo le dije: «No lo creas, porque no es un ángel del Señor, sino un agente del diablo». Y acto seguido lo llamé en voz alta a mi presencia y le pregunté si aún lo veía. Él me contestó: «Mira, aquí está delante de nosotros». Entonces mandé al muchacho recitar determinados salmos, diciéndole: «Si es un ángel de Dios, seguirá de pie. Si es un demonio, huirá». Él empezó a decir los salmos en voz alta, y yo en voz baja para mis adentros. De pronto dijo: «Se está derritiendo y se desvanece». DÍAZ Y DÍAZ, M. C., Valerio del Bierzo..., p. 293. «La oración continua, el ininterrumpido diálogo con Dios, o, para usar el vocablo preferido por el monacato docto, la teoría, o contemplación era, sin lugar a dudas, el supremo ideal del monacato antiguo». Así, «la recitación de los salmos era considerada como la mejor defensa contra los demonios y pasiones y el mejor reclamo para atraer los ejércitos angélicos». GARCÍA COLOMBÁS, M., Op. Cit., p. 545, 711 y 740 . San Millán «reçava bien sus oras, toda su salmodía, los imnos e los cánticos, toda la ledanía; rezava so salterio por uso cada día, con todo est lazerio avié grand alegría». DÍAZ Y DÍAZ, M. C., La vida de..., p. 92.

69 DÍAZ Y DÍAZ, M. C., Valerio del Bierzo..., p. 239.

70 BURTON-CHRISTIE, D., Op. Cit., p. 123.

71 «Velad, pues, no sabéis a que hora va a venir vuestro Señor. Pero sabed esto, que si el padre de familia supiese a que hora el ladrón habría de venir, velaría, y no dejaría minar su casa. Por tanto, también vosotros estad preparados; porque el Hijo del Hombre vendrá a la hora que no pensáis». Mateo, 24: 42.

72 Esto se debe a que el sueño del hombre se encuentra en estrecha relación con la digestión. «Los monjes observaban la vigilia no sólo manteniéndose despiertos durante la noche recitando su synaxis, sino esforzándose también por cultivar una vigilancia interior permanente». BURTON-CHRISTIE, D., Op. Cit., p. 194. Colombás dice que los «ayunos y velos nocturnas van de ordinario a la par en la doc- 
Para completar esta disciplina y evitar pensamientos impuros, el eremita debía tener todo su tiempo ocupado. El trabajo manual jugaba, por tanto, un papel muy importante en este camino hacia Dios ${ }^{73}$. San Valerio decía que «también los ayunos y los trabajos se han establecido para cercenar los placeres deshonestos» ${ }^{74}$. De esta manera, el santo practicaba la copia de las Sagradas Escrituras, «para consuelo de mi peregrinaje y como esfuerzo para la corrección de mi disciplina y mis conocimientos ${ }^{75}$, ya que todo el tiempo empleado en aspectos alejados de Dios son considerados tiempo perdido. Por ello, se reduce al mínimo los aspectos del mantenimiento vital del individuo y de su supervivencia llegando en algunos casos a situaciones extremas ${ }^{76}$.

En este sentido, tanto las tentaciones sufridas como las visiones que estos hombres tienen del Señor en múltiples ocasiones, bien podríamos considerarlas como alucinaciones fruto de estas extremas condiciones de vida. La falta de alimento y sueño, así como las duras penitencias infligidas, provocaban en estos hombres un comportamiento mental insano, así como una debilidad absoluta que les avocaba a una muerte inevitable, como así lo narraba San Valerio: «Por todo un periodo de veinte años seguidos, durante todo este tiempo, en medio de las continuas calamidades de mi vida, fui perdiendo mis fuerzas, y mi cuerpo debilitado por la flojera de todos mis miembros, vivía alentado apenas, hasta que al fin la piedad divina, que nunca olvida compadecerse de los que en ella tienen su esperanza, viendo mi incapacidad, ahogada en la ciénaga de este siglo, encontró una salida conveniente. El compasivo pastor que dio su alma por sus ovejas, no des-

trina y en las descripciones de la vida de los monjes antiguos". GARCÍA COLOMBÁS, M., Op. Cit., p. 582; EGEA VIVANCOS, A., «Monacato cristiano rupestre en el Éufrates», Antigüedad y Cristianismo, 22, (2005), p. 655.

73 ACEBRÓN RUíZ, J., La aventura nocturna: Claves del sueño en la literatura castellana medieval del siglo XVI, (Tesis doctoral inédita, Lleida, 2001, p. 75), [en línea]. Disponible en: http://www.tdx.cat/TDX-0821103-130658. [Consultado: 02/06/2010]. Colombás señala que «el trabajo manual constituye un elemento de gran importancia del ascetismo monástico de los primeros tiempos». Así, es «obra de penitencia y renuncia, constituye a menudo una mortificación de la carne». No obstante, no sólo era utilizado para mantener la totalidad de su tiempo ocupado sino también como un medio de subsistencia ya que, «habiendo renunciado voluntariamente a cuanto poseían, los monjes se habían convertido en pobres, $y$, como verdaderos pobres que eran, no les quedaba más que dos medios para resolver el insoslayable problema de la propia subsistencia: ganarse el pan con el sudor de su frente, o bien vivir de limosnas». Sin embargo, quedan excluidos determinados trabajos que no sean mecánicos, ya que el anacoreta debe estar continuamente concentrado en Dios. Así, «el monacato primitivo juzgó casi unánimemente que, si hay trabajos que implican desasosiego y distraen el espíritu, los hay también que favorecen la atención a Dios». Igualmente, el trabajo manual era utilizado para evitar el sueño y permanecer en vela. GARCÍA COLOMBÁS, M., op. cit., p. 546 y 553-554. No obstante, Mar Marcos apunta que «el trabajo manual nunca había sido un precepto para el asceta. En realidad, no había preceptos para los ascetas, hasta que se difundieron las Reglas monásticas y esto será ya en los siglos V, VI y siguientes. Hasta entonces, existen unos principios generales, que cada uno va experimentando y poniendo en práctica de acuerdo con las costumbres del lugar, con sus fuerzas y ambiciones y, sobre todo, con su cultura». MARCOS, M., Monjes ociosos..., p. 65.

74 DÍAZ Y DíAZ, M. C., Valerio del Bierzo..., p. 191.

75 Ibidem, p. 253.

76 Esto se debe a que «nuestros maestros estaban convencidos que de la debilidad del cuerpo se seguía la debilitación de las pasiones». GARCÍA COLOMBÁS, M., Op. Cit., p. 577. 
cuidó sacar su perdida oveja de un naufragio en el mar más profundo, y llevarla al ansiado puerto ${ }^{77}$.

De este modo, a través de estas prácticas, el eremita recorre un camino ascendente en el que purifica su pensamiento y su cuerpo se despoja de lo impuro, buscando, en cierto sentido, que cuerpo y alma se unan en uno sólo para acercarse a Dios, e impregnarse de su sabiduría divina ${ }^{78}$.

Para estos ascetas, el viaje místico era una de las experiencias más elevadas a las que un hombre podía aspirar, ya que constituía «un verdadero éxtasis, una salida del alma fuera de sí misma» ${ }^{79}$. Su fin y, con él, la recompensa ansiada, llegará el día en que la muerte acontezca a estos hombres ${ }^{80}$, como así describía San Valerio: «Como navecilla averiada por las violentas olas logra al fin arribar en el ansiado puerto, así yo indigno, como levantado de mi enterramiento y sepulcro, o expulsado de la tenebrosa cárcel del infierno, disfrutando de la luz preclara después de las tinieblas, no ceso de dar a Dios omnipotente inmensas gracias, porque al fin me ha permitido alcanzar con mi cuerpo ya sumamente avejentado el lugar de paz siempre tan deseado y con frecuencia tan duramente buscado. Y así confío en Él para que, de la misma manera que me mantuvo un tanto alejado de la vorágine del mundo, me haga obtener el triunfo y la palma victoriosa sobre el apestoso y maligno enemigo; y expiado del contagio de toda clase de pecados, según la súplica de mi penitencia, con aquellos que predestinó a otorgarme el descanso, me otorgue el fruto de mi sacrificio y la compañía de la vida eterna quien con el trofeo de la cruz ha destruido el imperio perecedero» 81 .

77 DÍAZ Y DÍAZ, M. C., Valerio del Bierzo..., p. 267.

78 «A través de estas alternativas, en las que se suceden renuncias, purificaciones e iluminaciones, el alma va avanzando por el camino de la perfección y va siendo admitida gradualmente en la intimidad divina. Dios se le manifiesta y le abre los ojos del corazón; y con humildad y acción de gracias penetra, finalmente, el monje en el reino del Espíritu». GARCÍA COLOMBÁS, M., Op. Cit., pp. 512-513.

79 Ibidem, p. 747.

80 Colombás apunta que es la Vita Antonii la que presenta este viaje como un camino ascendente y dinámico, "que, en vez de decrecer y aquietarse con los años, se va acelerando más y más». De esta manera, «la misma muerte aparece como el último estadio terrestre y, por así decirlo, la consumación de este perpetuo superarse». Ibidem, p. 512.

81 DÍAZ Y DÍAZ, M. C., Valerio del Bierzo..., p. 311. 
Cap03 14/11/2011 13:19 Página 80

$\infty$ 